\title{
Apply out-side mold decoration technique to Cosmetic Package Design
}

\author{
Shih-Wen Hsiao, Chih-Huang Yen, Chu-Hsuan Lee \\ Industrial Design Dep. \\ National Cheng Kung University, Tainan, 701, Taiwan \\ swhsiao@mail.ncku.edu.tw; jordan_yan@hotmail.com
}

\begin{abstract}
To conform to fashion tendency and market requirements, cosmetics always pursue for fashion and innovation, thus package design is confronted with problems of limited design elasticity, complex follow-up job sequences, environmental pollution caused by technology and cost of high reject ratio. The essay proposed to replace traditional coating process with out-side mold decoration technology to simplify cost, reduce cost, make design flexible, realize custom-made products according to requirement of clients, produce in a small scale and produce products with high quality, low cost and environmental which can meet requirements the market. Out-side mold decoration technology is to print patterns and characters in transparent films which will be coated over molding products after being transferred with high pressure and vacuum, and then, punching will be used to realize a three-dimensional coating in surface of products. Out-side mold decoration technology of the essay can be applied in products whose appearance are concerned. And besides cosmetic containers, it can be also applied in other relevant products such as powder box, eye shadow box and lipstick case, and in other industries like vehicle shell, 3C product shell and electrical appliances. In addition, CAE analysis technique and precision injection molding technology can be applied in technology development related to injection plastic products to shorten development time, improve product quality, and thus have a wide market application.
\end{abstract}

Keywords-cosmetics; out-side mold decoration, OMD; mold flow analysis

\section{INTRODUCTION}

It is human nature to pursue beauty. According to the need-hierarchy theory of Maslow (1970), when basic physiological needs are met, people will start to pursue higher needs; and when people have enough to eat and wear, they will start to pursue health and beauty with the former is to pursue extension of life and the latter is to pursue identification of others. However, they all can be regarded as requirements of health and beauty [1]. Generally speaking, the business opportunity of health and beauty is not a new concept. With the rapid development of social economy and the improvement of people's living standards, health and beauty have been paid great attention. In the aspect of consumption trend, the anti-aging ideas, individualism and self-expression have brought an individualized trend, thus cosmetics become necessities of people in their daily life. In the huge market opportunity, various products keep coming out one after another. General cosmetics are solid, liquid or cream without distinct appearance. Thus, they must have exquisite and distinct package design to express their characteristics, attract consumers, induce inner feelings and make them to buy them. Therefore, quality and design of appearance of cosmetics have a great influence on whether the products can be popular among customers.

The out-side mold decoration technology which is used to replace the traditional coating process can meet the environmental protection concept of EU regulations. The outside mold decoration technology adheres to the principle of protecting the global and respect life. Recently, the technology is just in its initial stage, thus that our company took the lead in introducing the new technology to simplify work, save cost, make design flexible, realize custom-making according to requirements of clients and produce in a small scale can not only help the company improve product competitiveness but also promote development the industry.

\section{A. Research motivation}

Analysis of problems in container production of traditional cosmetics:

(1) Limited design flexibility: traditional coating process is only targeted to pattern transfer in a plane. If colors change greatly, off color will be serious. Colors are difficult to control. And products with a large curved surface and a high depth can only use toner to mix plastics so as to realize single color injection, but the color will dull without changes.

(2) Complex follow-up work processes: traditional cosmetic containers techniques will have follow-up processing like baking varnishing, electroplating, gilding and printing according to requirements of shapes and patterns, but the second processing will have shortcomings like increasing production cost, extending production cycle and failing in automation.

(3) Environmental pollution: baking varnishing, electroplating, gilding and printing belong to wet-type coating, thus in the production process, chemical liquid, solvent and coating will generate industrial waste water and other pollution problems which will bring great harm to the environment. Under the strict supervision of 
environmental protection policies at home and abroad, for example, EU calls for a green product import qualification, traditional techniques are bound to be transformed or weeded out.

(4) High reject ratio: patterns and characters in surface of products are easy to drop, which will affect their appearance, and moreover, dropped printing ink can affect the health of customers. If traditional injected products have a surface treatment on shrinking, warped, pitting and bounding wires, appearance defects will be more obvious, thus the defect ratio is very high.

\section{B. Research objectives}

Based on the above analysis, the essay set up the following objectives according to the problems due to the current production technologies:

(1) Green product design

Out-side mold decoration (OMD) is a innovative 3D surface decoration technique which can be also called dry-type coating technique that can eliminate environmental problems of traditional cosmetic container coating. The technique is to is to print patterns and characters in transparent films which will be coated over molding products after being transferred with high pressure and vacuum, and then, punching will be used to realize a three-dimensional coating in surface of products. The manufacturing flows can meet the environmental protection standards of WEEE of the EU and RoHS, and the developed products conform to requirements of green resource industries.

(2) Changeable product appearance design:

The traditional surface coating technology is limited to plane surface and regional areas but to products with a curved shape and a high depth. OMD processes product appearance with high pressure and vacuum and it can generate various senses of touch and patterns and enlarge the curved shape, thus designers can create more products without regarding techniques so that customers have more choices and product competitiveness will be improved.

(3) Improved product reject ratio:

In design, cosmetic containers will have quality problems due to requirements of functions (like reinforcement rib and configure disk) such as shrinking, warped, pitting and bounding wires. And follow-up surface decoration treatment will make the defects more obvious and increase reject ratio. While, out-side mold decoration technology can solve the problem by covering a thin film in the surface so as to reduce reject ratio.

(4) Elastification of manufacturing techniques:
OMD technique is to print finished plastic or mental shell with patterns fit to product appearance with high pressure and vacuum and it belongs to out-side mold technique, thus off-line work can be carried out without affecting original injection machines. Meanwhile, it can design different patterns according to design requirements, make deign flexible and realize small scale production.

\section{RESEARCH FRAMEWORK}

Based on the current development processes, the essay adheres to the design principle of green and environmental protection and circulating utilization except research and development of package design. The development of new products through mold flow analysis and the advanced OMD technology will reduce cost and reject ratio.

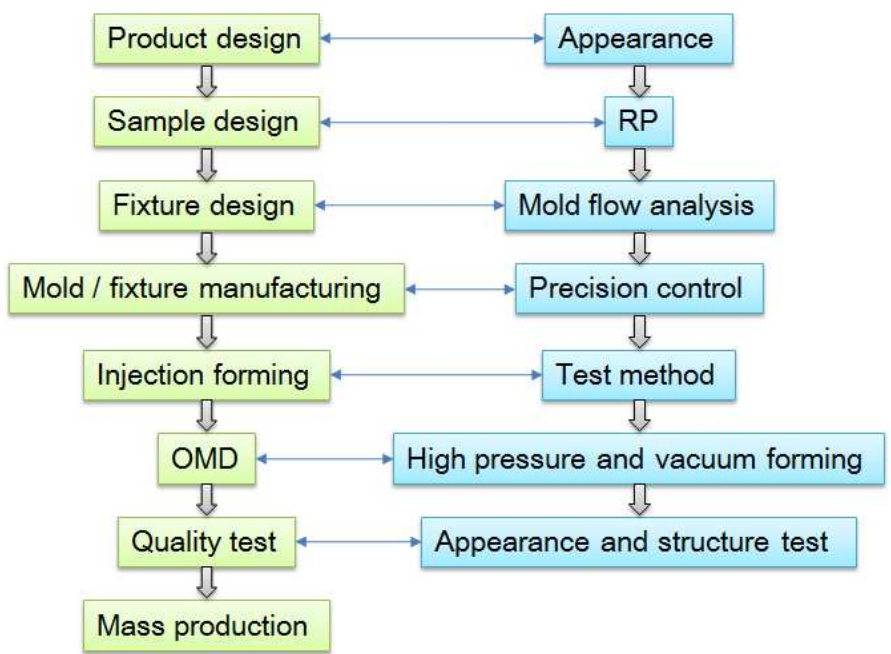

Fig. 1. Research framework and flows

Figure 1 is the research flow. The whole process from design and development to sample production applies the 3D computer aided drawing. And moreover, CAE is used to analyze and rectify mold flows in the process of manufacturing molds. The emphasis and innovation of the essay is to apply the OMD technology in appearance design of cosmetics and take high pressure and vacuum forming as a solution.

Table 1 indicated that in the process of research and development, details of key technologies and required equipments should be designed according to demands of development. 
Table 1. Key technologies and equipments of the flow

\begin{tabular}{|c|c|c|}
\hline NO. & main key technologies & main key equipments and materials \\
\hline 1 & product structure design & $\begin{array}{l}\text { software: use drawing software and } \\
\text { shaping software in product structure } \\
\text { design and configuration design of } \\
\text { powder box. }\end{array}$ \\
\hline 2 & $\begin{array}{l}\text { film construction and } \\
\text { pattern design }\end{array}$ & $\begin{array}{l}\text { texture }: \mathrm{ABS} \\
\text { thickness }: 0.125 \mathrm{~mm} \cdot 0.175 \mathrm{~mm} \\
\text { equipment : printing machine }\end{array}$ \\
\hline 3 & mold flow analysis & $\begin{array}{l}\text { software: use MoldFlow in mold flow } \\
\text { analysis to imitate changing situation of } \\
\text { injection molding products. }\end{array}$ \\
\hline 4 & $\begin{array}{l}\text { molding tool design and } \\
\text { production }\end{array}$ & $\begin{array}{l}\text { software: mapping software } \\
\text { equipment: processor }\end{array}$ \\
\hline 5 & $\begin{array}{l}\text { OMF out-side mold } \\
\text { decoration technology }\end{array}$ & $\begin{array}{l}\text { equipment: high pressure and vacuum } \\
\text { molder }\end{array}$ \\
\hline 6 & product testing & $\begin{array}{l}\text { equipments: lattice scraper, adhesive } \\
\text { force testing tape, image measuring } \\
\text { instrument, cupping machine, hot and } \\
\text { humid equipment }\end{array}$ \\
\hline
\end{tabular}

\section{CASE STUDY}

The essay used the innovative 3D surface decoration technology OMF as the development technology of appearance of the product to make product appearance design more flexible and meet green and environmental protection techniques by overcoming environmental problems of traditional techniques like coating and printing, high development cost, limited appearance design, high reject ratio and inapplicability in metal materials. Figure 2 and figure 3 is the initial concept which takes the shape of apple as a design direction. The designers tried to have a shape with a large curve, which is a challenge to the out-side mold decoration technology and textures

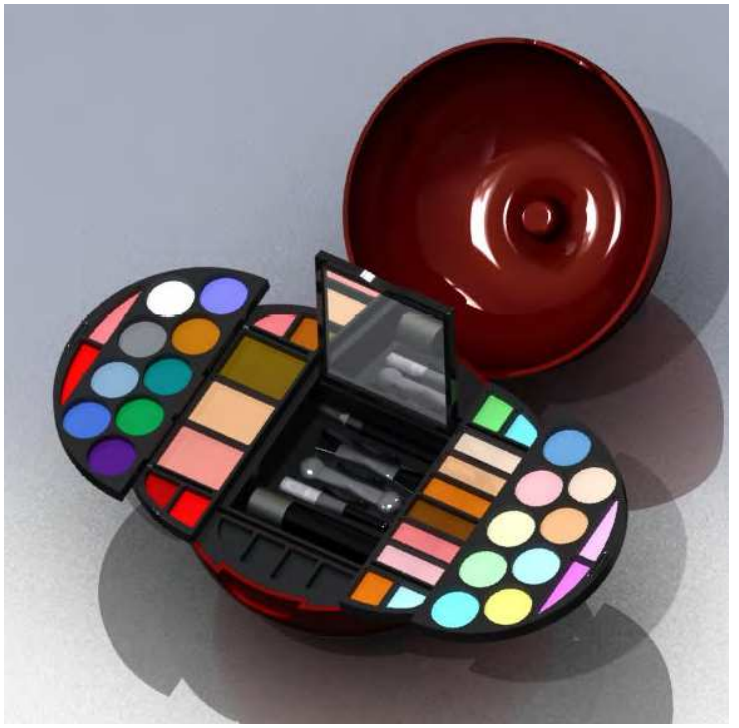

Fig. 2. A finished powder box by use of 3D drawing

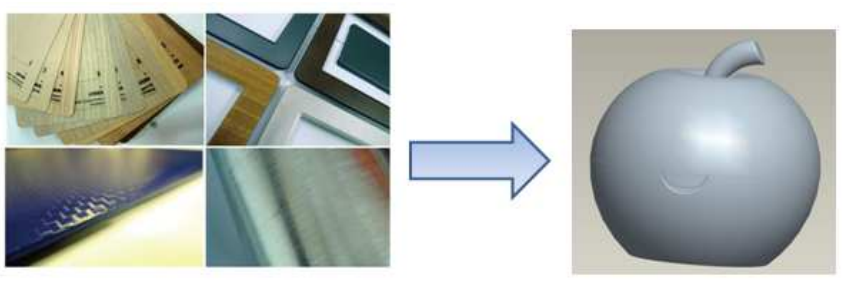

Fig. 3. Apple-shaped powder box which is covered with various decorative designs

Finally, complete content and organizational editing before formatting. Please take note of the following items when proofreading spelling and grammar:

\section{A. Out-side mold decoration technology (Out-side Mold Decoration, $O M D$ )}

Figure 4 indicates to fit plastic or mental shells in the appearance to decorate. Technologies which can make sense of touch, visual sense and functions meet requirements can be divided into two types, namely, OMF and OMR. Figure 5 indicates OMF (Forming Film) is to print patterns and characters in transparent films which will be coated over molding products after being transferred with high pressure and vacuum, and then, punching will be used to realize a three-dimensional coating in surface of products [2] [3] [4]. 


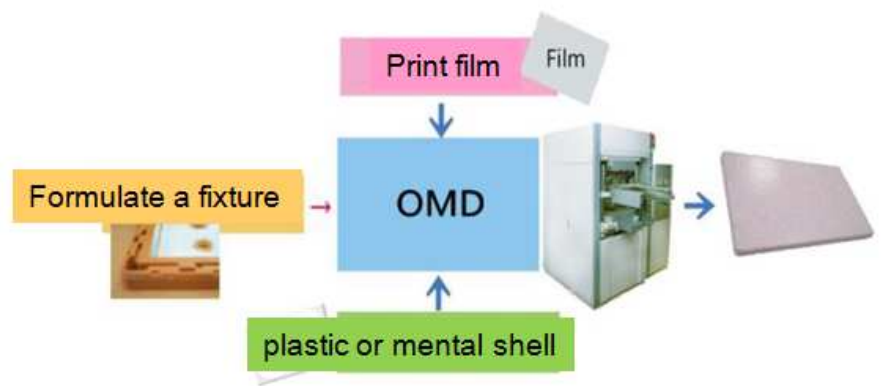

Fig. 4. Manufacturing flow of OMD

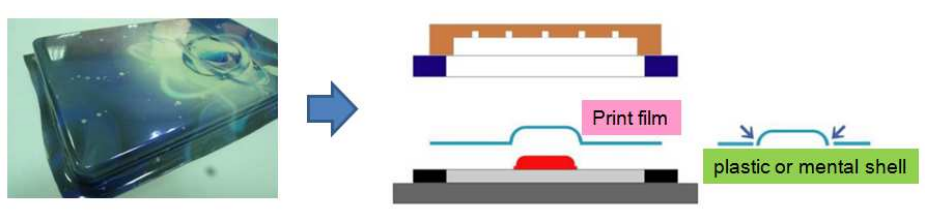

Fig. 5. Manufacturing flow of OMF in OMD

\section{B. Mold flow analysis}

The product is an apple-shaped cosmetic box which adopted one mold two holes side gluing with the hope of finding the most suitable flow path and waterway design through mold flow analysis without fusion lines and sealing positions in surface. Mold flow analysis before product development can reduce cost and failures so as to decrease reject ratio and flaws in product appearance. From the analysis results, we can know that suture lines and sealing positions are in end of round holes. The maximum injection pressure in the upper cover of the product is $144 \mathrm{MPa}$ with a clamping force of about 223 tons, and the maximum injection pressure in the lower cover is maximum injection pressure in the upper cover of the product is $144 \mathrm{MPa}$ with a clamping force of about 163 tons. In the initial stage of development of product molds, feasible forming analysis through mold flow analysis is as figure 6 shows. Through mold flow analysis, we can find the best flow path and waterway design [5] and control the maximum amount of contraction below $0.2 \mathrm{~mm}$ to make sure tightness of products, reduce mold trials, reduce development time and cost and improve product quality.

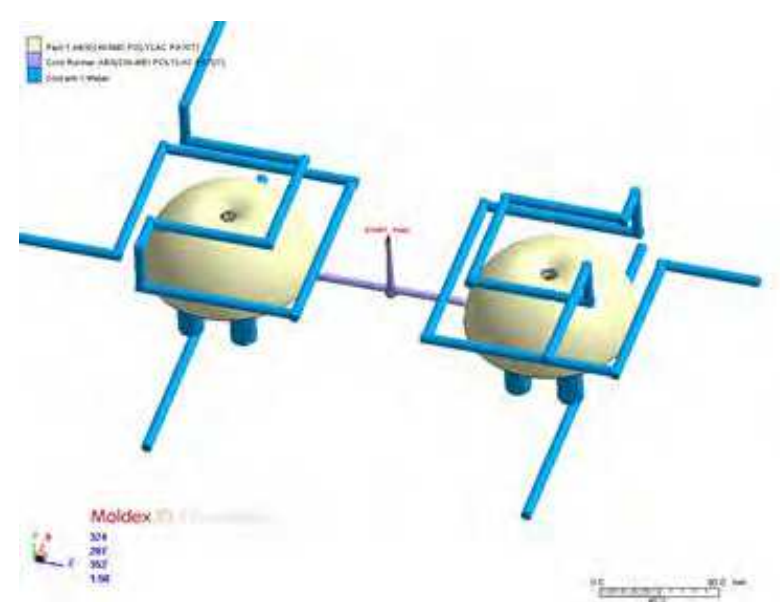

Fig. 6. Upper cover flow path and waterway design of the apple

\section{RESULTS AND DISCUSSION}

The final design after treatment of OMD is as figure 7 shows, and tests and inspections are included in the whole process.
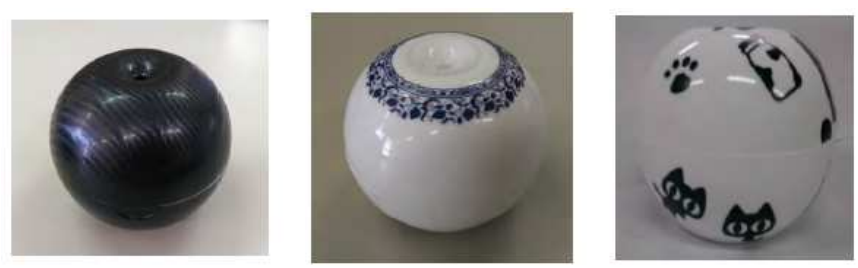

Fig. 7. Cosmetic powder box after the treatment of OMD technology

The The results of the green production:

1. Improve resource efficiency. Surface decoration of traditional plastic products will have a second processing after molded. The essay used OMF technology to develop cosmetic shells to simplify processes, reduce cost, improve product durability and production efficiency and improve yield to $90 \%-95 \%$.

2. Reduce materials. Traditional surface decoration is limited to production technology and can only produce product in a single form and design elasticity is limited. While, OMF surface decoration technique adopts off-line integral forming so as to avoid traditional color separation and disassembling, speed up design and production proceeding and save time and cost. Meanwhile, design changes just require change films to realize the diversified appearance, save molding cost and application of treatment liquid (such as electroplate liquid). Changes of film patters only can realize different appearance design, thus reducing 50\% mold application and over 10\% application of treating fluid (like electroplate liquid).

3. Reuse resource. The essay used ABS and AS plastic materials, which are generally recycled resources. Empty cosmetic boxes can be reused to carry other goods. And the recovery rate reaches to over $90 \%$.

* Corresponding author: jordan_yan@hotmail.com) 
4. others. Traditional surface decoration technologies have chemical fluid and waste water. OMF technique belongs to dry-type coating which can meet environmental protection standards of the EU stipulations, RoSH and WEEE.

Benefited from the changing international market, economic ability of developing countries has been improved. Cosmetics which are regarded as luxury goods before have been accepted by the public and have become an important consumption link in the world market. Therefore, cosmetic is regarded as one of star industries of the future and an important industry which has development prospect. The essay used OMF technology to develop environmental protection cosmetic containers with a large curved face and a high depth to make appearance design vary, reduce follow-up surface processing, decrease production cost, be environmental protective, save energy, reduce reject ratio, simplify techniques, save mold cost and realize elastification of production techniques. It can be expected that the innovation will bring more diversified development and become a leader in cosmetics.

\section{Acknowledgment}

The authors are grateful to the Ministry of Economic Affairs of Taiwan for supporting this research under CITD, Grant No. E10300018001-510.

\section{References}

[1] Maslow, A. H. (1970). Motivation and psychology of being. New York: D.Van Nostrand.

[2] 2. Rean-Der Chien, Hsien-Hsun Tseng, Chiu-Lan Yane, Shih-Tsun Huang and Shia-Chung Chen, (2007) Study on the Characteristics of Thermoforming for PC Films Used for In-Mold Decoration, NSC Project No.:NSC-92-2212-E-033-008,

[3] 3. S. Miyake et al. (2016) Dependence of the friction durability of extremely thin diamond-like carbon films on film thickness. Wear 356357,15 June,Pages 66-76.

[4] 4. C-Y Wong, K.Z. Liang, (1997) "Thermal Effects on the Behaviour of PET Films Used in the In-Mould-Decoration Process Involved in Plastics Injection Moulding", Journal of Materials Processing Technology, Vol. 63 pp.,510-513.

[5] 5. D. Pierick, R. Noller, (1991) The effect of processing Conditions on shrinkage, Society of Plastics Engineers, ANTEC, pp.252-258. 